\title{
Monitoring and Evaluating Progress towards Universal Health Coverage in India
} \author{
Systems Resource Centre, New Delhi, India \\ This paper is part of the PLOS Universal Health Coverage \\ Collection. This is the summary of the India country case \\ study. The full paper is available as Supporting Information \\ file Text S1.
}

Narayanan Devadasan ${ }^{1 *}$, Soumitra Ghosh ${ }^{2}$, Sunil Nandraj ${ }^{3}$, T. Sundararaman ${ }^{4}$

1 Institute of Public Health, Bengaluru, India, 2 Tata Institute of Social Sciences, Mumbai, India, 3 Public Health Foundation of India, New Delhi, India, 4 National Health

\section{Background}

Universal Health Coverage (UHC) is gaining in importance across the world. WHO defines UHC as "ensuring that all people can use the promotive, preventive, curative, rehabilitative and palliative health services they need, of sufficient quality to be effective, while also ensuring that the use of these services does not expose the user to financial hardship" [1]. While many countries have achieved UHC to a large extent, others are still on the path; India being one such country.

\section{Universal Health Coverage: The Policy Context in India}

UHC is not a new concept in India. The Bhore committee (1946) had recommended that India should have a health system that "is designed to provide [a full range of health care] for everyone who wishes to use it. ....everyone who uses the new service is assured of ready access to whichever of its branches he or she needs" [2]. However, since then the government has steadily diluted its promise of universal health care. In 1983, it only promised access to "universal provision of comprehensive primary health care services" [3] and in 2002, UHC became reduced to access to "universal immunisation services" [4]. The government's flagship programme National Rural Health Mission (NRHM), launched in 2005, did include strengthening health services, but there was no mention of universal provision of health services [5]. It was only in 2011, when the government of India commissioned a High Level Expert Group (HLEG) that UHC once again entered the lexicon of health policy makers. The HLEG report recommended that India should achieve UHC by 2022 by increasing government finances and by strengthening provision of government health services [6]. This report was accepted by the Planning Commission and is the focus of the health chapter of its 12th five-year plan [7].

\section{Monitoring and Evaluation for UHC}

The Ministry of Health $(\mathrm{MoH})$ has a digitised health management information system (HMIS) that collects data every month from all the government health facilities across the country.

Collection Review articles synthesize in narrative form the best available evidence on a topic. Submission of Collection Review articles is by invitation only, and they are only published as part of a PLOS Collection as agreed in advance by the PLOS Medicine Editors.
However, the HMIS has a major weakness; it does not collect information from the private health sector. Since the private sector is the main provider of many health services in India, the HMIS reports are incomplete. Thus policy makers and managers are unable to determine the true health status of the citizens of the country.

To understand the extent to which people are covered by various health services, the policy maker then relies on periodic household surveys administered by independent agencies $[8,9]$. Outpatient and inpatient services and health expenditure are captured through the decennial morbidity surveys [10]. Infant mortality rates and occasionally the maternal mortality ratio can be obtained through annual Sample Registration Surveys [11]. Some states have recently started an annual health survey [12].

\section{Progress towards UHC in India}

Given the paucity of routine and disaggregated data, it is difficult to assess the status of UHC in India. We used data from household surveys done in 2004, 2005, and 2009 to calculate the population, service, and financial coverage. We selected indicators on the basis of their availability across these surveys. In 2009, only $53 \%$ of pregnant women had received three check-ups and only $61 \%$ of infants were fully immunised. Disaggregating by socioeconomic parameters, shows that only $27 \%$ of pregnant women belonging to the poorest quintile had received a full antenatal check-up. Nearly $50 \%$ of all women who had an antenatal checkup had to make direct out-of-pocket (OOP) payments for their examination.

Among patients who fell ill, more than $80 \%$ sought care at a formal health facility. Similarly more than $70 \%$ of women had delivered at a health facility in 2009 . However, among the poorest quintile this figure was only $55 \%$. Also, most of the patients or women had to make OOP payments to receive these services (Figure 1).

Citation: Devadasan N, Ghosh S, Nandraj S, Sundararaman T (2014) Monitoring and Evaluating Progress towards Universal Health Coverage in India. PLoS Med 11(9): e1001697. doi:10.1371/journal.pmed.1001697

Published September 22, 2014

Copyright: (c) 2014 Devadasan et al. This is an open-access article distributed under the terms of the Creative Commons Attribution License, which permits unrestricted use, distribution, and reproduction in any medium, provided the original author and source are credited.

Funding: ND received a travel grant from the WHO to attend a workshop on $\mathrm{UHC}$ at Singapore. He also received a small honorarium from WHO to write this manuscript. The funders had no role in study design, data collection and analysis, decision to publish, or preparation of the manuscript.

Competing Interests: The authors have declared that no competing interests exist.

Abbreviations: HMIS, health management information system; OOP, out-ofpocket; UHC, universal health coverage.

* Email: deva@iphindia.org

Provenance: Not commissioned; part of a Collection; externally peer reviewed 


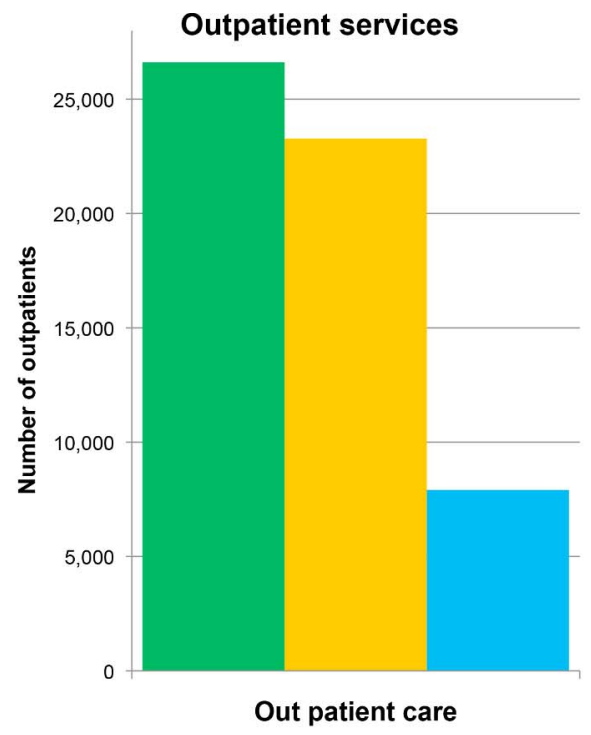

- Number of patients who were sick

Number of patients who sought care in a facility

- Number of patients who did not have any $\mathrm{CHE}$

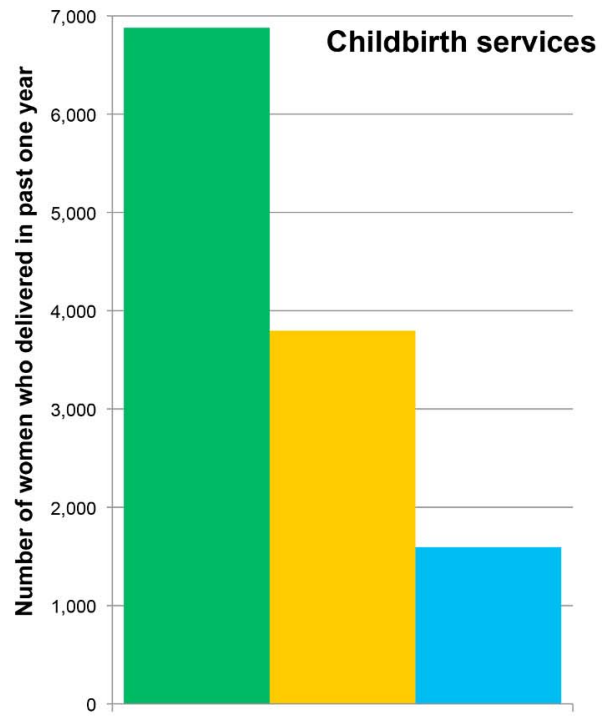

Deliveries

- Deliveries in past year

Deliveries in institutions

Deliveries with no $\mathrm{CHE}$

Figure 1. Service and financial coverage for outpatient and natal services in India (2004). Source: NSS 60th round, 2004 [10]. doi:10.1371/journal.pmed.1001697.g001

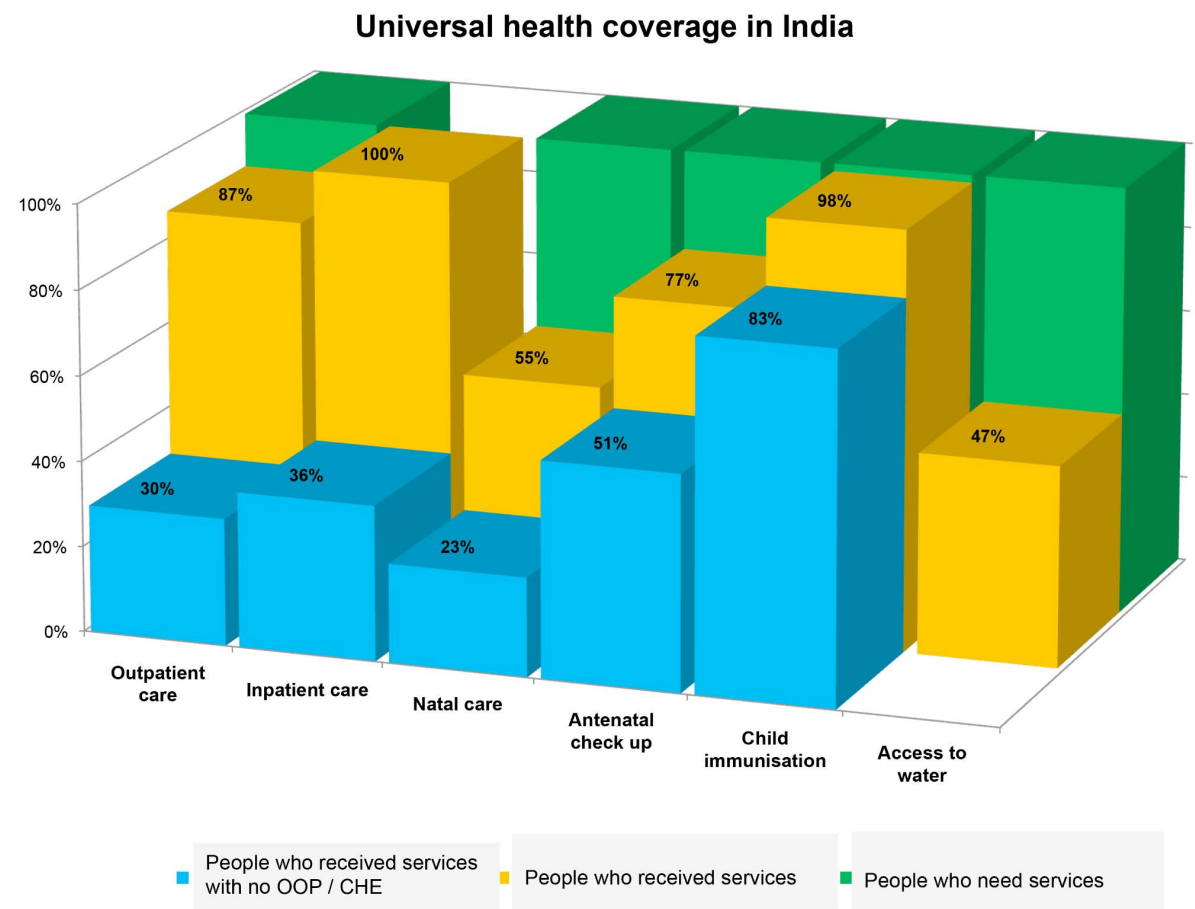

Figure 2. Universal health coverage for selected health services in India in 2004. Source: NFHS 3, DLHS 3, NSS 60th round, and Coverage evaluation Survey $[8-10,15]$.

doi:10.1371/journal.pmed.1001697.g002 
Only $47 \%$ of households in India had access to drinking water within their premises. The rest of the households had to walk distances ranging from 100 metres to a few kilometres to get water.

\section{Conclusions and Recommendations}

India has pledged to achieve UHC by 2022. We found that while the population is reasonably covered by preventive and curative health services, financial coverage is lacking for most of these services (Figure 2). When we disaggregate coverage by population subgroups, we consistently find that people living in rural areas, belonging to lower caste households, and having a low economic status use the services much less compared to other groups.

For India to move towards UHC, the first step should be to provide financial protection against medical expenses. Although there are currently many subsidised health insurance schemes for poor people [13], they do not address the main source of OOP payments, which is ambulatory care and medicines [14]. One of the measures that the government of India could take to improve coverage would be to provide access to free medicines for all

\section{References}

1. WHO (2014) What is universal coverage? Available: http://www.who.int/ health financing/universal_coverage definition/en/. Accessed 7 April 2014.

2. Bhore J (1946) Report of the health survey and development committee survey Vol 1. New Delhi: Government of India Press.

3. Ministry of Health and Family Welfare (1983) National health policy. New Delhi: Government of India.

4. Ministry of Health and Family Welfare (2002) National health policy 2002. New Delhi: Government of India.

5. Ministry of Health and Family Welfare (2005) National rural health mission. New Delhi.

6. Bang A, Chatterjee M, Dasgupta J, Garg A, Jain Y, et al. (2012) High level expert group report on Universal Health Coverage for India. New Delhi: Public Health Foundation of India.

7. Planning Commission (2012) Twelfth five year plan (2012-2017): social sectors. New Delhi: Government of India.

8. International Institute for Population Sciences (2007) National family health survey: 2005-06. Mumbai: International Institute for Population Sciences. individuals seeking care, which would reduce OOP payments considerably. The second measure would be to extend existing services to the most vulnerable sections of the population, that is the poorest, aboriginals, and others. With these two measures in place, the government could undertake additional actions to attain UHC. Another important stage would be to monitor progress against specific milestones. Because the current HMIS is inadequate, the government must employ periodic household surveys to capture the necessary information.

\section{Supporting Information}

\section{Text S1 The full country case study for India.} (DOCX)

\section{Author Contributions}

Analyzed the data: SG ND. Wrote the first draft of the manuscript: ND. Contributed to the writing of the manuscript: ND SG SN TS. ICMJE criteria for authorship read and met: ND SG SN TS. Agree with manuscript results and conclusions: ND SG SN TS.

9. International Institute for Population Sciences (2009) District level household and facility survey. Mumbai: Government of India.

10. National sample survey organisation (2006) Morbidity, health care and condition of the aged. New Delhi: Government of India.

11. Registrar General of India (2013) Estimated birth rate, death rate and infant mortality rate, 2012. SRS Bull 48: 1-6.

12. Registrar General and Census Commissioner (2011) Annual health survey 2010-11: Uttar Pradesh. New Delhi: Registrar General and Census Commissioner.

13. La Forgia G, Nagpal S (2012) Government-sponsored health insurance in India: are you covered? Washington (D.C.): World Bank. Available: http://elibrary. worldbank.org/content/book/9780821396186.

14. Shaktivel S, Karan A (2010) Deepening health security in India: evidence from national sample surveys since 1980s. Econ Polit Wkly 45: 55-60.

15. UNICEF (2009) Coverage evaluation survey. New Delhi: UNICEF. 